AC 2011-2898: PANEL SESSION - SOCIALIZATION OF ENGINEERING STUDENTS: A WORKPLACE APPROACH

Susan M. Matney, North Carolina State University

(C)American Society for Engineering Education, 2011 


\section{Socialization of Engineering Students: A Workplace Approach}

The education of today's engineer is a complex process. Graduates are expected to not only be technically literate and of an engineering mindset, but also competent team players capable of the independent thought required of innovation. Such a demanding process requires collaborative intervention from a varied subset of sources.

There is an educational adage that asserts "when the student is ready, the teacher will appear." While certainly it is the case that the curriculum is adequate to the task of preparing young minds for their roles as engineering professionals, the role of the teacher is not exclusive to the classroom. In the case of fortunate engineering students, the teacher will take many forms. Potentially among these is a network of faculty, employers and cooperative education professionals. This highlights the "value added" of experiential learning. By expanding the classroom boundaries beyond the campus, the student broadens his/her educational reach while simultaneously enhancing workplace competencies.

This discussion panel will be comprised of representatives (aka teachers) from each of these three groups; faculty, employers, and co-op professionals. Each panelist will bring their perspective to bear on their responsibility as a "teacher" of engineering students. Dimensions to be explored will include managing expectations, creating appropriate boundaries, and defining one’s self-efficacy. 